\title{
Mnemonic Strategies: Helping Students with Intellectual and Developmental Disabilities Remember Important Information
}

\author{
Jeffrey P Bakken* \\ Bradley University, Peoria, Illinois
}

Submission: July 20, 2017; Published: July 28, 2017

*Corresponding author: Jeffrey P Bakken, Associate Provost for Research and Dean of the Graduate School, Bradley University, Peoria, Illinois, USA, Email: jbakken@fsmail.bradley.edu

\section{Abstract}

The ability to remember new and unfamiliar material is very important for the success students with intellectual and developmental disabilities. As students move through the different grade levels new information is transferred to them and the types of content presented is often more complex. Mnemonic strategies have been proven to help students recall information by making it easier to remember, more meaningful, and more concrete. Mnemonic strategies are an effective study tool which can be utilized with students with intellectual and developmental disabilities and applied to an array of content areas. This manuscript will present a variety of mnemonic strategies that can be very useful when working with students with intellectual and developmental disabilities to improve their vocabulary knowledge.

\section{Introduction}

Mnemonic instruction is a way to help students with intellectual and developmental disabilities remember new information more effectively, efficiently and easily. It involves linking unfamiliar content information with familiar already known information through the use of a visual picture or letter/word combination. The use of mnemonic instruction helps students with intellectual and developmental disabilities learn unfamiliar content more easily. "Mnemonics are effective when they speed up learning, reduce confusion among similar items, and enhance long-term retention and application of the information" [1] p. 160.

The first mnemonic strategy to be discussed is the keyword method which is a memory-enhancing strategy that students can implement to help them increase the initial learning and retention of facts. For students with intellectual and developmental disabilities this can be very beneficial to them as they often encounter new vocabulary in schools. This method incorporates both auditory and visual cues to enhance meaningfulness of the information to be learned and to promote strong associations between questions and answers [2]. In addition to the keyword method, other methods such as the pegword method as well as the implementation of reconstructive elaboration mnemonic strategies have proven results across many studies and have shown to be effective for middle school and high school age students with learning disabilities [3] as well as other students.
In addition, "mnemonic devices, such as acrostics, acronyms, narratives and rhymes, can assist in making abstract material and concepts more meaningful for individuals" [4] p. 349.

\section{Research History of Mnemonic Strategies}

Mnemonic strategies are systematic procedures for enhancing the memory and making information more meaningful. There are many different retrieval strategies that have been developed and that can be implemented to aid in the recall of new and unknown information. Educational research has repeatedly demonstrated that the way information is initially encoded facilitates the memory and the recall of this information much better for the learner. The fundamental aspect in developing mnemonic strategies is to find a way to relate new information to information that is already in the long-term memory of students. If this connection can be made, the memory of this information has the potential of being remembered for a very long time.

Mnemonics instruction with school age students is commonly implemented as an instructional strategy for teaching word recognition and vocabulary. The effectiveness of the use of these strategies is well documented. The use of mnemonic strategies by students, including secondary and college level, shows that the implementation of these strategies helps them remember 2 to 3 times more factual information, helps them recall information over delayed recall periods, and they report that they enjoy using them over more traditional approaches. Other 
research findings "provide evidence that instruction involving the use of mnemonic devices does enhance a student's formal reasoning skills and that this has the potential for application of knowledge to more varied tasks" [4] p. 11. In addition, "the use of mnemonics with college age students might have enough potential for making learning easier and possibly more fun" [5].

It may also be helpful to mention what mnemonic strategies are not. Mnemonic strategies do not represent a "philosophy" of education. Mnemonic strategies should be taught to students to help them remember information that may otherwise be difficult for them to remember. Mnemonic strategies are also not an overall teaching method or curricular approach. The focus of mnemonic strategies is so specific that they are intended to be implemented to enhance the recall of the components of any lesson for which memory is needed. These mnemonic strategies should be implemented to help students recall new and unfamiliar information and are not specifically focused on improving comprehension. It should be noted that students who are trained mnemonically also perform better on comprehension tests of that specific content [6,7], but that is generally because the implementation of the mnemonic strategies helps them remember more information that can be applied on comprehension tests. Finally, it should be emphasized that mnemonic strategies are not the "cure all" for success in school.

\section{Mnemonic Strategies}

\section{Acrostics}

Acrostics are a sentence that is developed to help the person retrieve letters. These letters then represent something that the person needs to remember. The sentence is a (catchy) way to make the information more meaningful and easier to remember. For example:

\section{Every Good Boy Deserves Fudge}

This example helps an individual remember the lines of the treble clef (e, g, b, d, and f).

An example of the use of acrostics in an astronomy class is:

My Very Educated Mother Just Served Us Nine Pizzas

This particular example helps the person remember the order of the planets of the solar system (Mercury, Venus, Earth, Mars, Jupiter, Saturn, Uranus, Neptune, and Pluto). It must be noted that students must first know the vocabulary for the strategy to be effective. For example, if a student does not already know the names of the planets, the acrostic will be of no help to them in remembering their order.

\section{Acronyms}

Another popular form of mnemonics is the use of acronyms. Acronyms are words that are developed from the first letter of words that are to be remembered. The following examples demonstrate use of acronyms:
To remember the Great Lakes the acronym HOMES could be used:

Huron

Ontario

Michigan

Erie

Superior

To remember the colors of the rainbow the implementation of the acronym ROY G BIV could be taught to students:

Red

Orange

Yellow

Green

Blue

Indigo

Violet

It must be noted that students must first know the vocabulary for the strategy to be effective. For example, if a teacher wants to teach their students to recall the names of the Great Lakes, the acronym that has been developed to help students remember will be of no use in remembering the names if the student does not already know the actual names of the Great Lakes. Also, students need to be taught how to use the process. If they are not taught how to use the acronym to assist them in studying, they will not be able to recall the information. For example, it is very common for students to respond to the question, "What are the five Great Lakes?" with the answer HOMES. In this example, the student has either not practiced the strategy enough to recall the desired information or the teacher has not properly linked the acronym properly with the information the students are supposed to recall. The student recalls simply the acronym without understanding the content. The acronym cannot just be presented to the students or posted in the classroom. Students must have proper amounts of time practicing this technique and be properly taught how to effectively use the acronym so they can implement it independently and remember the proper information associated with the acronym.

\section{Keyword method}

The keyword method is a strategy that can be implemented to learn new and unfamiliar vocabulary words within any content area of instruction. It takes information that is unfamiliar to a student and makes it more meaningful and concrete through the use of a picture which makes it easier for the student to remember. When developing a keyword strategy you should follow the 3 R's: reconstructing, relating, and retrieve [2]. The use of the 3R's is as follows: 
Reconstructing: First you need to develop a keyword. A keyword is a word that is familiar to the student's vocabulary, can be easily developed into a picture, and sounds like the actual word that is to be learned;

Relating: Next, create a picture that depicts the keyword interacting with the definition

Retrieve: Lastly, the teacher needs to teach the process of how the student must go through the steps to effectively recall and remember the new vocabulary word and meaning.

An example of the use of this strategy can be seen when teaching the word peavy and its meaning, hook [2]. The word peavy means hook.

Develop keyword-Pea-it is familiar to students, acoustically similar to peavy and can be easily pictured.

Develop a picture of a pea on the end of a hook linking the keyword and the definition of the word.

Teach the process: "When I say what does peavy mean, first think of the keyword pea (peavy-pea), then what was happening with the pea, the pea was on the end of a hook, then the answerhook."

It is very important to not forget to teach the students the process of how to remember and recall the needed information (Step 3). Just developing and showing students mnemonic pictures will not improve their recall of vocabulary knowledge.

\section{Reconstructive elaborations}

Reconstructive elaborations are mnemonic strategies implemented when content area learning is presented. It involves students learning information taken from a content area textbook that they need to remember. There are four types of reconstructive elaborations that have been developed: symbolic, mimetic, acoustic, and the first letter strategy [8-10]. The definition and an example of each type of reconstructive elaboration is as follows:

Symbolic: The concept the student needs to know is an abstract concept, but familiar (1st US Policy) to the student. A symbol is used to represent something to help the student remember. Example: Uncle Sam representing the US and their stance in the war.

Mimetic: Student knows the word, but not meaning or the meaning is inaccurate. An example is trenches: Student is familiar with the word, but not meaning. Student is shown a picture of a trench with soldiers in it getting sick and dying.

Acoustic: This makes up most of the vocabulary that students need to remember. For this vocabulary, it is usually a totally unfamiliar word to the student and the student does not know the definition of that word. In essence, this is the same strategy as the keyword method, but was renamed since this information was specifically related to content area information (i.e., science, geography or social studies).

First letter: A combination of Acronym and Key Word strategies. For example, imagine a picture of an Allied van on fire with a person saying FIRE! Teacher asks what are the Allied Powers? Student thinks of keyword-Allied Van. What is happening with the Allied Van? The van is on fire. What does FIRE stand for? France, Italy, Russia, and England. Those are your answers. The picture and mnemonic methods alone will not be as beneficial to your students as teaching them the process of remembering the pictures and how to retrieve the important to-be-learned information [8].

\section{Double keyword method}

When the previous strategies described will not work another strategy is the double keyword method. When a teacher is trying to teach somewhat related information that is important for students to learn, but all the information is unfamiliar to them it can be a difficult process. In this case, a double keyword strategy might be implemented. This might be used when a person has to be able to go forwards or backwards to recall important information $[11,12]$. Remembering the states and their capitals would be an example where students might not know the name of a state or its capital. An example for recalling states and their capitals would be as follows: A teacher could ask "what is the capital of Wisconsin? or, Madison is the capital of what state?" In this example, the student would basically need to remember two different strategies using the same picture that was developed. One strategy would be implemented for the state and one strategy would be implemented for the capital which means they need to be able to go forwards or backwards with the process to recall the needed information. An example of how this technique might be taught is as follows:

Teacher: The keyword for Wisconsin is whisk broom and the keyword for Madison is maid.

Teacher Asks: What is the capital of Wisconsin?

Teacher Instructs Students: First, think of the keyword for Wisconsin (whisk broom), then think about what is happening in the picture (a maid is cleaning with a whisk broom), and finally your answer-Madison. The teacher could also go in the other direction by asking Madison is the capital of what state? In this example the student should first think of the appropriate keyword for Madison (maid), then the next step would be to try and remember what was happening in the picture (oh, there was a maid and she was cleaning with a whisk broom in the picture), and finally the student should decode the other keyword for the appropriate answer which is "whisk broom" and the answer would be Wisconsin.

This is another method to help students with and without disabilities learn information.

\section{Study skills and students}

It is the role of the teacher to identify information where 
mnemonic strategies could be implemented, and provide support to students so they can learn to evaluate how the use of mnemonics could support their study skills. Students should be encouraged to work with their teacher to develop strategies that can assist with learning new content in other classes and how to apply mnemonic strategies. An effective way to assist students with intellectual and developmental disabilities in the use of mnemonics is to implement a team approach in developing the best strategies for the learner. The more individuals involved in the process will help with developing more ideas. During team meetings, brainstorming is an effective technique. This technique can be implemented so that there are many options to consider from many different people and each choice can be evaluated as to which might be the most effective. If there is not a good choice skip it and come back to it later. The young adult learner should be involved in the planning process and the team should look directly at the content that needs to be learned. To start, teachers need to not only develop the mnemonic strategies and pictures, but teach the process of how to remember new information. Over time, students should be developing the mnemonic strategies and pictures and by doing so this will enhance the student experience and make it more likely that they will implement these strategies in future classes and improve their recall of content area information.

\section{Conclusion}

A difficult task for many is to remember new, difficult or uninteresting material. This is a very common for many different kinds of students, especially for students with intellectual and developmental disabilities. Learners are required to learn more information and more complex content. Mnemonic strategies have been proven to help individuals remember information by making it easier to remember and more concrete. These strategies work with students with intellectual and developmental disabilities and it can be applied to any type of content. Although mnemonic strategies can be very beneficial, it is important to choose the correct method or it will not benefit the learner.

\section{References}

1. Shmidman A, Ehri L (2010) Embedded picture mnemonics to learn letters. Scientific Studies of Reading 14(2): 159-182.

2. Mastropieri MM (1988) Using the keyword method. Teaching Exceptional Children 20(2): 4-8.

3. Wolgemuth JR, Cobb R, Alwell M (2008) The effects of mnemonic interventions on academic outcomes for youth with disabilities: A systematic review. Learning Disabilities Research \& Practice 23(1): $1-10$.

4. Laing G (2010) An empirical test of mnemonic devices to improve learning in elementary accounting. Journal of Education For Business 85(6): 349-358.

5. Higbee KL (1994) More motivational aspects of an imagery mnemonic. Applied Cognitive Psychology 8(1): 1-12.

6. Mastropieri MA, Scruggs TE, Fulk BJM (1990) Teaching abstract vocabulary with the keyword method: Effects on recall and comprehension. J Learn Disabil 23: 92-96.

7. Scruggs TE, Mastropieri MA, McLoone BB, Levin JR, Morrison C (1987) Mnemonic facilitation of learning disabled students' memory for expository prose. Journal of Educational Psychology 79: 27-34.

8. Mastropieri MA, Scruggs TE (1989) Reconstructive elaborations: Strategies for adapting content area information. Academic Therapy 24: 391-406.

9. Mastropieri MA, Scruggs TE, Whittaker MES, Bakken JP (1994) Applications of mnemonic strategies with students with mild mental disabilities. Remedial and Special Education 15(1): 34-43.

10. Scruggs TE, Mastropieri MA (1989) Reconstructive elaborations: A model for content area learning. American Educational Research Journal 26: 311-327.

11. Mastropieri MA, Scruggs TE, Bakken JP, Brigham FJ (1992) A complex mnemonic strategy for teaching states and their capitals. Learning Disabilities Research \& Practice 7(2): 96-103.

12. Mastropieri MA, Scruggs TE (1994) Effective instruction for special education. $\left(2^{\text {nd }} e d n\right)$, Austin, PRO-ED, USA.

\section{Your next submission with Juniper Publishers will reach you the below assets}

- Quality Editorial service

- Swift Peer Review

- Reprints availability

- E-prints Service

- Manuscript Podcast for convenient understanding

- Global attainment for your research

- Manuscript accessibility in different formats

( Pdf, E-pub, Full Text, Audio)

- Unceasing customer service

Track the below URL for one-step submission https://juniperpublishers.com/online-submission.php 